\title{
JOURNAL.RU
}

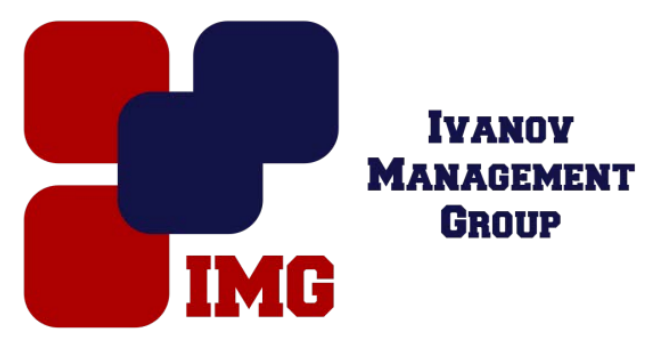

Егоров В.Г., Васечкин М.А., Маслов И.Н., Латышев Т.К. Воронежский государственный университет инженерных технологий Воронеж, Россия

doi: 10.18411/lj-30-04-2017-3-02

idsp 000001:1j-30-04-2017-3-02

\section{Разработка нормализованного ряда корпусов фильтров очистки воды из коррозионно-стойких сталей}

\section{Аннотация}

В работе приведены результаты научно-исследовательской и опытноконструкторской работ в области создания долговечных и экологически безопасных систем подготовки питьевой воды модульного типа.

Разработаны и изготовлены конструкции фильтров различного назначения. При изготовлении корпусов фильтров одной из операций технологического процесса является ротационная раскатка цилиндрических заготовок, которая позволила снизить массу фильтра и устранить негативное влияние сварных швов.

Проведенные экспериментальные исследования показали, что цилиндрические образцы из коррозионно-стойкой стали после ротационной раскатки имеют высокую прочность и способны выдерживать многочисленные перепады внутреннего давления.

Ключевые слова: системы водоподготовки, корпус фильтра, коррозионно-стойкая сталь, ротационная раскатка.

В настоящее время одной из глобальных проблем является обеспечение населения и предприятий пищевой промышленности качественной питьевой водой. Качество питьевой воды зависит от ряда факторов, одним из которых является материал, из которого изготовлены корпуса и коммуникации водоочистных систем. Мировыми и отечественными производителями (фирмы Atoll, Aquapro, Honeywell, Harmsco, Milipore, Промфильтр, Аквафор и др.) 
выпускаются картриджные, в том числе мультипатронные, засыпные и обратноосмотические фильтры для очистки воды, а также фильтры бактериальной очистки с использованием ультрафиолетового облучения.

Корпуса фильтров, особенно предназначенных для бытового использования, в основном изготавливают пластиковыми. К преимуществам таких корпусов следует отнести низкую себестоимость изготовления и минимальные весовые характеристики. В то же время при взаимодействии воды с внутренней поверхностью пластикового корпуса фильтра неизбежно вымываются высокомолекулярные соединения, представляющие опасность для здоровья человека.

Упомянутого недостатка лишены корпуса, изготовленные из коррозионностойкой стали. Основным функциональным и несущим элементом данных корпусов является емкость в виде колбы которая изготавливается из листового проката с использованием гибочно-сварочных операций с последующим электрохимическим полированием. Однако, даже самая тонкая зачистка и полировка продольных и кольцевых сварных швов не может выровнять механические свойства и геометрические параметры сварного шва, околошовной зоны и основного металла. В результате околошовная зона зачастую является тем местом, где зарождается межкристаллитная коррозия с постепенным распространением усталостных трещин внутрь корпуса фильтра, что приводит в конечном итоге к разрушению его стенки. Для увеличения срока службы нержавеющего корпуса при его изготовлении производители вынуждены использовать лист большей толщины, что приводит к увеличению материалоемкости и удорожанию конструкции. Кроме того, в районе сварных швов из-за недостаточной чистоты поверхности скапливаются всевозможные загрязнения, болезнетворные бактерии, что негативно сказывается на качестве очищенной жидкости.

Исключить наличие сварных швов можно путем перехода к цельной бесшовной конструкции колбы, полученной вытяжкой из листа. Однако, существенные габариты колб фильтров высокой производительности требуют для их производства мощного специализированного оборудования.

Другим наиболее перспективным и экономичным способом устранения негативного влияния сварных швов является использование в технологическом процессе изготовления колб для фильтра операции ротационной раскаткисварной цилиндрической заготовки. Ротационная раскатка выполняется 
на универсальном токарно-винторезном станке, оборудованном специальной оснасткой для раскатки трубных заготовок [1].

При ротационной раскатке цилиндрических заготовок происходит пластическое упрочнение материалас одновременным утонениемстенок. Результаты экспериментальных исследований цилиндрических образцов из стали AISI 304диаметром 90 мм и толщиной стенки 1 ммпоказали, что при относительной деформации по толщине стенки от $10 \%$ до $20 \%$ после ротационной раскатки временное сопротивление разрыву $\sigma_{\text {в возрастает }}$ приблизительно в 2 раза, а их ресурс при испытаниях пульсирующим внутренним давлением составил в среднем свыше 350000 циклов без разрушения[2, 3].

Применение в технологическом процессе изготовления корпусов фильтров из коррозионно-стойких сталей операции ротационной раскатки позволило создать нормализованный ряд установок для очистки воды различного назначения и производительности, имеющие при гарантированно высоких ресурсе, надежности и экологической безопасности более низкую себестоимость изготовления и материалоемкость (в среднем такие конструкции имеют на $30 \%$ меньшую массу по сравнению с аналогичными корпусами изготовленными без применения ротационной раскатки).

В частности, были разработаны и изготовлены корпуса для фильтров (рисунок 1), которые в зависимости от потребностей, могут выполнять следующие задачи: осветление и удаление механических частиц и взвешенных веществ, ионообменное умягчение воды, сорбционную или обратноосмотическую очистку, деферризацию воды, бактерицидную очистку с использованием ультрафиолетового излучения. Разработана конструкция для использования в походных условиях.

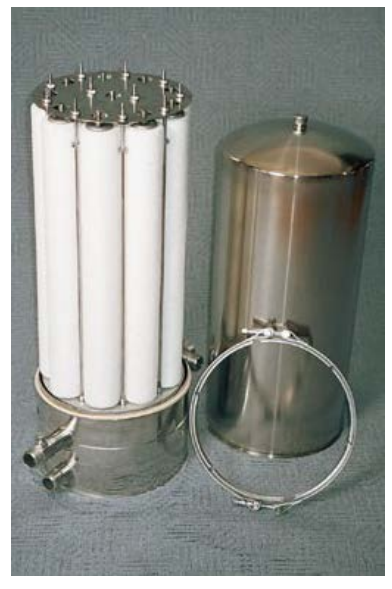

a)

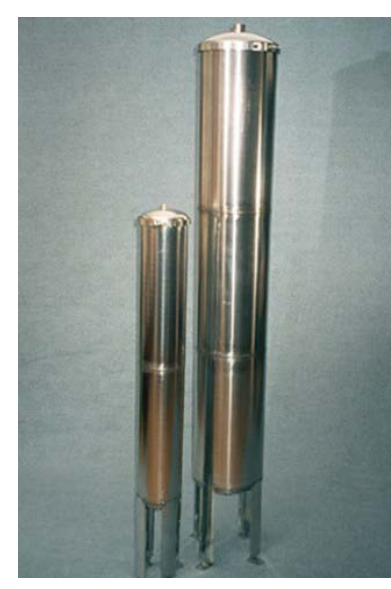

б)

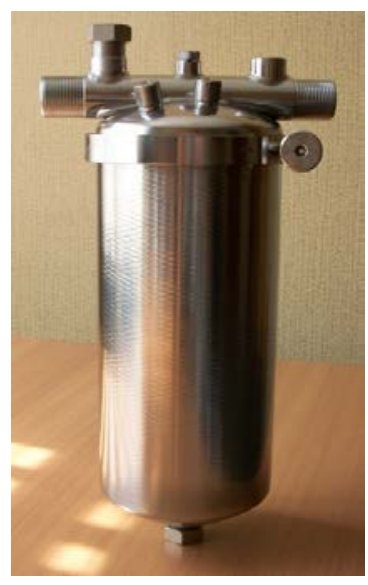

b) 


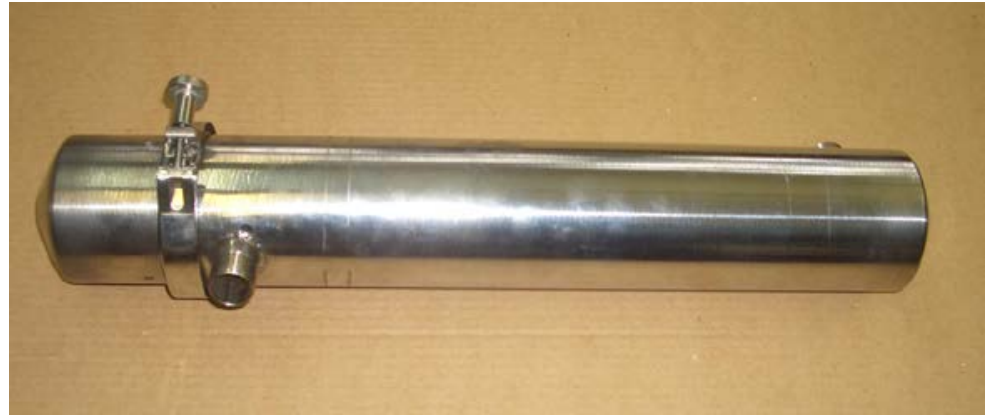

2)

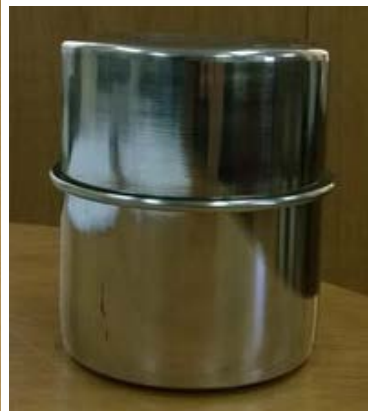

d)

Рисунок 1 - Образиы фильтров из коррозионно-стойкой стали: $а$ - мультикартриджныйфильтр для осветления и удаления механических частии и взвешенных веществ; б - фильтр для ионообменного умягчения водь;; в фильтр для деферризаџии водь;; г - фильтр для бактерицидной очистки ультрафиолетовымизлучением; дпоходный фильтр.

В основе конструкций фильтров лежат защищенные патентами РФ разработки [4-6].

В таблице 1 приведены основные параметры и характеристики корпусов фильтров, изготовленных из коррозионно-стойкой стали.

Разработанные конструкции фильтров, в зависимости от потребности, могут применяться как отдельные модули, так и собираться в систему для выполнения комплексных задач. Следует отметить, что коррозионно-стойкие стали являются инертными к воздействию различных жидкостей, используемых в жизнедеятельности человека. Таким образом, нормализованные размеры корпусов фильтров позволят создавать системы требуемой производительности очистки не только воды, но и других жидкостей и растворов.

Таблийа 1.

Параметры и характеристики корпусов фильтров

\begin{tabular}{|c|c|c|}
\hline Параметр или характеристика & Ед. измерения & Значение \\
\hline Рабочее давление & атм. & до 6 \\
\hline Максимальное кратковременное рабочее давление & атм. & до 12 \\
\hline Производительность по очищенной воде & $\mathrm{m}^{3} /$ ч & до 60 \\
\hline Диаметр колбы & мм & от 90 до 600 \\
\hline Толщина стенки колбы & мм & от 0,8 до 3 \\
\hline Высота колбы & мм & до 1500 \\
\hline Условный проход & мм & до 200 \\
\hline $\begin{array}{c}\text { Количество одновременно устанавливаемых } \\
\text { картриджей }\end{array}$ & шт. & до 60 \\
\hline $\begin{array}{l}\text { Материал корпуса фильтра } \\
\text { АISI 304, AISI 321, AISI } \\
\text { 316. }\end{array}$ \\
\hline
\end{tabular}


1. Shaping high-longevity components of corrosion-resistant pipes by rotary rolling /M.A. Vasechkin, O.Yu. Davydov,V.G. Egorov, I.N. Maslov //Chemical and Petroleum Engineering. -September, 2016. - Vol. 52, № 5-6 - PP. 392-397

2. Determination of the optimum conditions at the processing of high-strength corrosion-proof pipelines /M.A. Vasechkin, V.G. Egorov, I.N. Maslov, A.B. Kolomenskiy //Research Journal of Applied Sciences. - 2016. - T. 11, № 4. -PP. 85-87.

3. Investigation of influence of extent of deformation at rotary rolling-off on cyclic life of precision corrosion-proof pipelines /M.A. Vasechkin, O.Yu. Davydov,V.G. Egorov, I.N. Maslov //International Journal of Applied Engineering Research.- 2015. - Vol. 10, № 21.PP. 42649-42653.

4. Пат. 2381820 РФ. Фильтр для очистки жидкости / В.В. Толстиков, В.Г. Егоров, В.В. Голуб // Бюл. - 2010. - № 5.

5. Пат. 2422188 РФ. Фильтр очистки жидкости / В.В. Голуб, В.Г. Егоров, В.В. Толстиков // Бюл. - 2011. - № 18.

6. Пат. 2430768 РФ. Фильтр очистки жидкости / В.Г. Егоров, В.В. Голуб, В.В. Толстиков // Бюл. - 2011. - № 28
\end{abstract}

